\title{
Novel Polymorphism in a Promoter of MBL2 Gene Result in Lower MBL Expression in Chronic Infection Caused by HCV
}

\author{
Paywast Jamal Jalal \\ Biology Department \\ College of Science \\ University of Sulaimani \\ Sulaimani, Iraq \\ paywast.jalal@univsul.edu.iq
}

\begin{tabular}{l}
\hline \hline Article Info \\
\hline Volume 5 - Special Issue: $4^{\text {th }}$ \\
International Conference on the Health \\
and Medical Science : Medical \\
Researches Improve Life Quality \\
(ICHMS 2020) \\
DOI: \\
10.24017/science.2020.ICHMS2020.13 \\
Article history: \\
Received: 03 October 2020 \\
Accepted: 11 October 2020 \\
\hline
\end{tabular}

Keywords:

MBL, SNPs, PRRs, L-ficolin, H-ficolin, $\mathrm{HCV}$ infection.

\begin{abstract}
The Pathogen Recognition Receptors (PRRs) is an active protein in the immune system. The PRRs that secreted in the liver and we addressed were L-ficolin, $M B L$ and H-ficolin. Previous studies revealed that both $M B L$ and L-ficolin were hampered the $H C V$ entry and infectivity. However, H-ficolin impact still needs to be addressed more so as determining their role during $\mathrm{HCV}$ infection. For these purposes, we aimed to determine the effect of different level in the serum of these proteins on the HCV infection and treatment outcome. Initially, we selected (25) $\mathrm{HCV}$ positive patients and (25) HCV negative control patients from the Trent Cohort and Regional Haemophiliac Study and to present the differences in serum concentrations of $M B L, H$ - and L-ficolin. The level of these proteins was measured by ELISA method and compared with each other based on the detected SNPS by PCR and sequencing methods in the responsible genes. Our results showed that the polymorphism at position -221 in the MBL2 promoter significantly reduce the level of MBL protein more than the SNP at position -551. Interestingly, a new deletion of six nucleotides [AGGAAG] detected in the promoter at position -319 to -324 that succeeded by four other mutations at position $-328,-336,-349$ and -427 in most of the analyzed sequences. The 6bp deletion was statistically decreasing

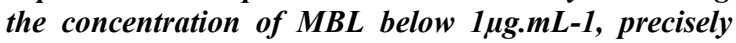
among non-responder patients. In conclusion, the existence of the new deletion in the promoter region of $M B L 2$ gene and the additional newly detected polymorphisms, reduce the level of $M B L$ protein and as a result impacts on the response to treatment among $\mathrm{HCV}$-infected patients.
\end{abstract}




\section{INTRODUCTION}

Human liver tissue expresses soluble pattern recognition receptors (PRRs) in response to infection and inflammation [reviewed in 1]. Two important classes of these receptors are the collectins and the ficolins. Collectins and ficolins both bind to repeating patterns of carbohydrates associated with the surface of bacterial and viral pathogens, and particularly viral glycoproteins. These complement-activating proteins directly bind HCV virions through interactions with the virus-encoded glycoproteins E1 and E2. These interactions result in the direct neutralization of the entry [2] and the complement cascade activation through interaction with the serine proteases MBL-Associated Serine Proteases (MASP-1 and MASP2) [3]. HCV-encoded proteins actively inhibit activation of the complement cascade [4, 5], suggesting that this component of the immune system contributes to the elimination of virus particles and infected cells. If inactivation of the complement cascade is required for the establishment of persistent replication, the activity of these pattern recognition receptors might contribute to protection against chronic $\mathrm{HCV}$ infection. This area of the immune reaction to $\mathrm{HCV}$ is currently poorly understood and warrants further research.

As well as a potential protective effect of lectins and ficolins in HCV infections, it is also possible that expression of these proteins and activation of MASP-1 results in activation of hepatic stellate cells, producing extracellular matrix and ultimately resulting in accumulation of fibrotic tissue [6]. Role of both ficolins and lectins are still unclear during HCV pathogenesis, but this might constitute an essential mechanism of liver damage in chronic infections [7].

The PRR genes polymorphisms have a direct impact on the susceptibility to infections [8] and the severity of infection caused by HCV. Moreover, the molecular clones of the allelic variants of L-ficolin have different abilities to recognize HCV particles [9]. It remains to be demonstrated if these phenotypic differences affect the degree of infectivity in $\mathrm{HCV}$-infected individuals.

\section{LITERATURE REVIEW}

The component of the complement system considered as a role maker in response to any viral disease. During infection, the soluble proteins in this system named as pattern recognition receptors (PRRs) activate the immunity and trigger the pathogen receptors. The PRRs, Lficolins and $\mathrm{H}$-ficolin and MBL (mannose-binding lectin) are active lectins in the immune system which secreted in the liver and has a role in the initiation, regulation, and amplification of the immune response $[10,11]$. They activate the lectin complement pathway and promote opsonization [12-14].

The PRRs gene polymorphisms were effect on the activity of the PRR proteins, which may up-regulate the risk of developing severe case due to the fluctuating the concentration of these proteins [15]. The previous study revealed that the single mutation in the $M B L 2$ gene was related to the fetal loss [16], infant recurrence of disease [17] and adult severity and chronicity of infection [18]. On the other hand, the higher level of MBL has a role in increasing the inflammation in patients with diabetes mellitus [reviewed by 19].

The SNPs in the MBL2 Promoter were identified at Nucleotide $-550(\mathrm{H} / \mathrm{L})$, nucleotide -221 $(\mathrm{X} / \mathrm{Y})$ and the -66 and +4 in the $5^{\prime} \mathrm{UTR}(\mathrm{P} / \mathrm{Q})[20]$. Three other structural mutations found in the $M B L 2$ exon 1 called D, B and C alleles at codon 52, 54 and 57, respectively that impair MBL multimerization then decreases binding to the ligand which as a result causes an impair of complement activation [10].

Our previous results shown that purified MBL [2] and L-ficolin [9], which are secreted by the liver, directly inhibit entry of $\mathrm{HCV}$ into target cells. However, $\mathrm{H}$-ficolin that also secreted by 
the liver still no evidence suggested their direct role in the innate immune response to HCV infection. Furthermore, it is not known whether serum concentrations of these molecules which affected by the gene polymorphisms were impacts HCV infection or treatment outcome. In this study, we addressed the previous SNPs that detected in the promoter of the MBL2 gene. When the sequence analyzed, the 6bp deletion was detected in the promoter region, which decreased the level of MBL protein and impacting the response to treatment among non-responder patients.

\section{METHODS AND MATERIALS}

Samples

Total of 50 samples was recruited for this study from three cohorts group of chronic HCV and Haemophilia patients also HCV-ve group as a control [Table 1]. The samples of the serum were kindly obtained from the Trent HCV cohort with the permission of Virology Research Group in Faculty of Medicine and Health Sciences, University of Nottingham, United Kingdom. The samples labelled with UKN (United Kingdome Nottingham) followed by the genotype/subtype and the patient number in each cohort. Different serum samples for each patient were selected for ELISA analysis which collected during infection and treatment then retrieved from $-80^{\circ} \mathrm{C}$. The same samples were used for genotyping of $M B L 2$. The selection of the samples in each HCV infected cohorts was based on the different level of each protein (high, medium, and low level) and the response to the treatment [SVR (Sustained Virological Responder), RR (Relapsed Responder) and NR (Non-Responder)].

Table 1: Number of Patients Recruited in This Study for Both ELISA and Genotyping.

\begin{tabular}{cccccc}
\hline \multirow{2}{*}{ Cohorts } & \multirow{2}{*}{ No. of Patients } & \multicolumn{2}{c}{ Response to Treatment } & \multicolumn{2}{c}{ No. of Samples } \\
\cline { 3 - 6 } & Status & No. of Patients & ELISA & PCR \\
\hline Control / HCV-ve & 25 & - & - & 25 & 4 \\
\hline \multirow{2}{*}{ Chronic HCV } & \multirow{2}{*}{15} & SVR & 6 & & \\
& & NR & 5 & 219 & 15 \\
\hline \multirow{2}{*}{ Haemophilia / HCV } & \multirow{2}{*}{10} & RR & 4 & & \\
\hline
\end{tabular}

\section{ELISA}

The HCV in the serum samples were inactivated using the inactivated buffer. The inactivation method followed in this study was a solution composed of the nonionic surfactant Triton X100 which can destroy the viral glycoproteins and resulted in a loss of infectivity [21]. All the samples diluted in an inactivating buffer 2\% TBSTX100 [TBS, Triton X-100] then used for ELISA and preserved at $4^{\circ} \mathrm{C}$ before analysis.

\section{MBL Binding Assay}

The level of MBL was detected using ELISA method based on Brown [22] with some modification. The MaxiSorp ${ }^{\circledR}$ plates (Nunc, Denmark) were coated with $50 \mu \mathrm{L}$ mannan $\left(1 \mu \mathrm{g} \cdot \mathrm{mL}^{-1}\right)$ in a coating buffer $[0.1 \mathrm{M} \mathrm{NaHCO} ; \mathrm{pH}=9.5]$ in duplicate. After overnight incubation at $4^{\circ} \mathrm{C}$, wells were incubated for $2 \mathrm{hr}$ at room temperature (RT) with $200 \mu \mathrm{L}$ blocking buffer [Phosphate Buffered Saline (PBS) and 0.1\% (v/v) Tween-20] then the wells were washed three times with wash buffer [10mM HEPES; $1 \mathrm{M} \mathrm{NaCl} ; 5 \mathrm{mM} \mathrm{CaCl}_{2} ; 0.1 \%$ (v/v) Tween $20 ; \mathrm{pH}=7.4$ ]. $50 \mu \mathrm{L}$ of each previously inactivated serum samples was diluted $1 / 5$ in wash buffer and added in duplicate to each well. Purified MBL $\left(1 \mu \mathrm{g} \cdot \mathrm{mL}^{-1}\right)$ used as a standard control and serially diluted 1/12.5 in the TBSTX100 and wash buffer. The plates incubated overnight at $4^{\circ} \mathrm{C}$. Before antibody binding the washing repeated then in each well $50 \mu \mathrm{L}$ of anti-rMBL were added [polyclonal antiserum to recombinant MBL, diluted 1/700 in Wash Buffer] then incubated for $2 \mathrm{~h}$ at RT. Wells were washed and incubated $1 \mathrm{hr}$ at RT with $50 \mu \mathrm{L}$ 
of 1/2000 dilution of alkaline phosphatase (AP) conjugated monoclonal anti-rabbit IgG (A2556 , Sigma) in wash buffer. The wells washed again and added $100 \mu \mathrm{L}$ pNPP ( $\rho$-Nitrophenyl phosphate) substrate (Sigma Fast N-2770, Sigma). The OD at 492nm was determined after 20min incubation at RT, and the results were compared to the standard curve made be a serially diluted purified MBL.

\section{Ficolin Binding Assay}

The level of both L-ficolin and H-ficolin were evaluated by ELISA method with some modification from Krarup [23]. MaxiSorp ${ }^{\circledR}$ ELISA plates (Nunc, Denmark) coated with $50 \mu \mathrm{L}$ Acetylated Bovine serum albumin (BSA) $\left[50 \mu \mathrm{g} \cdot \mathrm{mL}^{-1}\right]$ in phosphate-buffered saline (PBS). Following overnight incubation at $4^{\circ} \mathrm{C}$, wells blocked with PBS-Tween buffer [PBS; $0.05 \%$ Tween $20 ; 5 \%$ milk] then washed three times with TBS-Tween $[10 \mathrm{mM}$ Tris- $\mathrm{HCl} ; 140 \mathrm{mM}$ $\mathrm{NaCl} ; 0.05 \%$ Tween $20 ; 5 \mathrm{mM} \mathrm{CaCl} 2 ; \mathrm{pH}=7.4]$. The inactivated serum diluted in $10 \mathrm{mM}$ TBST-Ca [TBS; $10 \mathrm{mM} \mathrm{CaCl}_{2} ; 0.05 \%$ Tween 20] and TBSTX100, then added in duplicate and incubated overnight at $4^{\circ} \mathrm{C}$. Recombinant and purified ficolin $\left[4 \mu \mathrm{g} . \mathrm{mL}^{-1}\right]$ used as a standard and serially diluted 1/12.5 in TBST-Ca and TBSTX100 buffers then added to the coated wells in duplicate. After washing 3X, both primary antibodies, biotin-labelled anti-human L-ficolin antibody (GN5, 0.5 $\left.\mu \mathrm{g} \cdot \mathrm{mL}^{-1}\right)$ and h-Ficolin-3 purified goat IgG (AF2367, R\&D system/USA) used for detecting of L-ficolin and $\mathrm{H}$-ficolin, respectively, were added then incubated for $2 \mathrm{hrs}$ at room temperature (RT). Wells washed again (3X) and incubated with a 1:1000 dilution in wash buffer of an anti-mouse IgG (FC-specific) alkaline phosphatase antibody produced in goat (Sigma) and monoclonal anti-goat/ sheep IgG alkaline phosphatase antibody produced in mouse (Sigma), respectively. The washing repeated three times with TBS-Tween. The pnitrophenyl phosphate substrate (pNPP) substrate (Sigma) used for visualizing the binding. Measuring the absorbance by the Microplate reader at $405 \mathrm{~nm}$ (Fluostar Omega/ Microplate reader, BMG/LABTECH-UK) after 20-30 min incubation at RT. Level of ficolin was quantified by comparison to a generated standard curve from diluted serum with a defined Lficolin and $\mathrm{H}$-ficolin concentration.

\section{Direct Polymerase Chain Reaction}

A single-copy gene sequence up to $450 \mathrm{bp}$ was directly from the serum. For this method, we used Thermo Scientific Phusion Blood Direct PCR kit (F-5475) according to the manufacturer instruction and all the primers used for this study were designed and analyzed previously by Thio et al. [19]. MBL2 promoter amplified using MBLP550F [ACTCTGCCAGGGCCAACGTA] and MBLP221R [TGATGAGCAGTGGGGATCCTA]. A single PCR reaction was made up with $0.5 \mu \mathrm{L}$ of the inactivated serum sample, $0.5 \mu \mathrm{L}(5 \mathrm{pmol})$ of both the sense and the antisense primer, $10 \mu \mathrm{L}(2 \mathrm{X})$ Phusion Blood PCR Buffer, $0.6 \mu \mathrm{L}$ $\mathrm{MgCl}_{2}, 1 \mu \mathrm{L}$ EDTA, $0.4 \mu \mathrm{L}$ of High Fidelity Taq which were added in a $20 \mu \mathrm{L}$ reaction volume. Amplification was carried out with one cycles of initial denaturation at $98^{\circ} \mathrm{C}$ for $5 \mathrm{~min}$, and 35 cycles of denaturation at $98^{\circ} \mathrm{C}$ for $15 \mathrm{sec}$, annealing at $63^{\circ} \mathrm{C}$ for $5 \mathrm{sec}$, and extension at $72^{\circ} \mathrm{C}$ for $15 \mathrm{sec}$. A final extension step performed at $72^{\circ} \mathrm{C}$ for $2 \mathrm{~min}$.

\section{Sequencing}

Amplified PCR products sequenced using the Sanger method and by Applied Bioscience (UK). Both primers used for amplifying the fragment were used for sequencing. Also, two more internal primers used for sequencing $M B L 2$ promoter, which was: MBLP550R [CAGCTGATTCCCCTCCAGGAC] and MBLP221F [GGGATTCAGGTGGCAGATGG]. The sequences were analyzed by both MEGA7 Ink program and an online http://multalin.toulouse.inra.fr software.

\section{Confirmation of the Deleted Nucleotides in the Promoter of MBL2}

Deletion of $6 \mathrm{bp}$ detected in the $M B L 2$ promoter region of when the sequences analyzed in some patient's sample. The following steps were followed to confirm the presence of the deletion:

\section{Cloning and Transformation}

To confirm the deletion in the promoter, the previously amplified fragment from serum was purified using GenElute ${ }^{\text {TM }}$ PCR cleanup kit (Sigma-Aldrich) according to the manufacturer's instructions and then cloned into a vector using pcDNA $^{\mathrm{TM}} 3.1$ Directional TOPO Expression 
Kit (Invitrogen life technologies). Briefly, Topo cloning reaction prepared as follow: $0.5 \mu \mathrm{L}$ from each of Topo vector and the salt solution was mixed gently with $2 \mu \mathrm{L}$ of the purified insert and completed to $10 \mu \mathrm{L}$ of sterile water. The mixture was incubated first at $22^{\circ} \mathrm{C}$ for $1 \mathrm{hr}$, then directly on ice for $5 \mathrm{~min}$.

The transformation was done as follow: $1.25 \mu \mathrm{L}$ of the ligated insert were mixed with the $25 \mu \mathrm{L}$ competent cell (Stellar ${ }^{\mathrm{TM}}$ competent cell, ST0231) and followed by incubation on ice for $30 \mathrm{~min}$. At $42^{\circ} \mathrm{C}$, the cells were heat-shocked during $45 \mathrm{sec}$, then immediately transferred to the ice for $5 \mathrm{~min}$. The transformed product was mixed with $250 \mu \mathrm{L}$ preheated SOC medium and incubated $1 \mathrm{hr}$ at $37^{\circ} \mathrm{C} .100 \mu \mathrm{L}$ of the transferred cells were cultured on a pre-warmed LB agar plate (containing $100 \mu \mathrm{g} \cdot \mathrm{mL}^{-1}$ Ampicillin) followed by incubation overnight at $37 \square \mathrm{C}$.

\section{Transformant Analysis}

The positive transformants were analyzed by directional PCR and by sequencing.

\section{Colony PCR}

The positive transformants were tested by direct PCR without the need for extraction, using two sets of primers; T7 [5'-TAATACGACTCACTATAGGG-3'] as a forward primer and BGH [5'-TAGAAGG CACAGTCGAGG-3'] as a reverse primer. The cloned gene was amplified by PCR kit- HotStar Taq polymerase kit. An aliquot of the PCR made up by mixing a portion of the colony with $1.5 \mu \mathrm{L} 10 \mathrm{X}$ buffer, $0.6 \mu \mathrm{L}$ of each of the primer, $0.5 \mu \mathrm{L} d N T P s$, and $0.075 \mu \mathrm{L}$ enzyme then completed with water to $12.5 \mu \mathrm{L}$. The PCR program was initially started with a heat activation step for $15 \mathrm{~min}$ at $95^{\circ} \mathrm{C}$ followed by 25 cycles of denaturation for $20 \mathrm{sec}$ at $95^{\circ} \mathrm{C}$, annealing for $20 \mathrm{sec}$ at $55^{\circ} \mathrm{C}$, and extension for $1.30 \mathrm{~min}$ at $72^{\circ} \mathrm{C}$. Lastly, another cycle of extension for $2 \mathrm{~min}$ at $72^{\circ} \mathrm{C}$ was performed.

\section{Sequencing}

The sequencing was done for plasmids that the colony screening on gel gives the correct size. The plasmids were prepared using Gene Elute ${ }^{\text {TM }}$ Plasmid Miniprep Kit (Sigma-Aldrich) according to manufacturer protocol. The sequencing performed using both $\mathrm{T} 7$ and $\mathrm{BGH}$ as external primers and both MBLP550R and MBLP221F as internal primers. The sequences were aligned and analyzed with the reference sequence, Accession no. NG_008196.1, from NCBI.

\section{Statistical analysis}

The analysis was performed by the GraphPad Prism 7 to determine the association between the SNPs and the concentration of each protein. The level of each protein determined by normalizing with the specific standard proteins used for each one. The difference in the median levels for different categories was assessed by one way ANOVA test analysis. For all the analysis, the significant evaluated when the $\mathrm{P}$-value $<0.05$.

\section{RESULTS}

\section{Measuring the Level of MBL by ELISA}

The normalized value from the ELISA analysis showed no statistically significant increase in the median level between the chronic and haemophilia patients when compared to the control group, which are HCV-ve [Figure 1]. The level of the protein among the chronic patients was increased in most of the patients; however, among the haemophilic patients, the level of MBL was remained in the same range as the HCV-ve samples. 


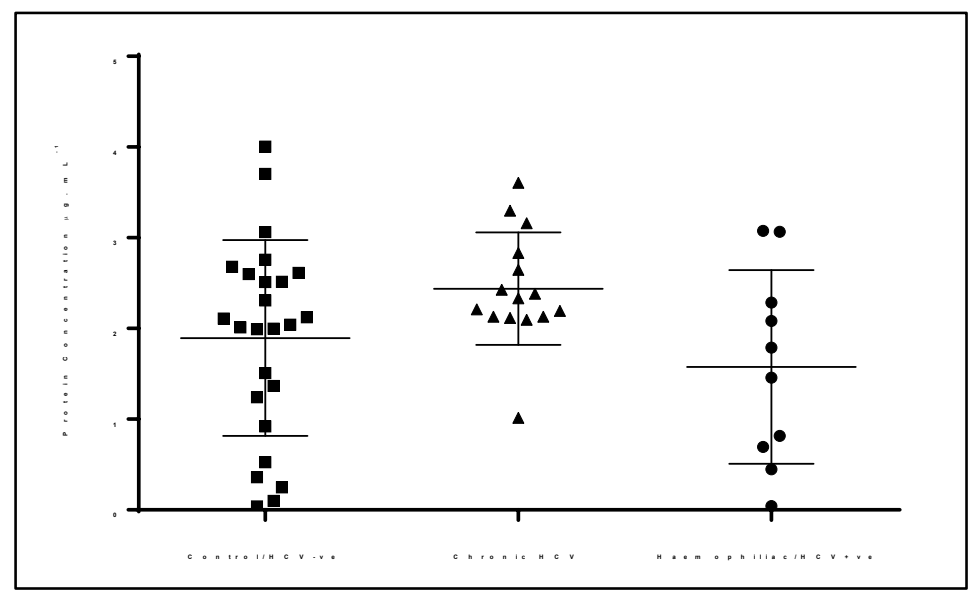

Figure 1: Comparison between Serum MBL levels between HCV infected patients and HCV-ve group. These samples which their MBL level presented in the graph were selected to address the 6bp deletion in the MBL2 promoter. Each dot is the Median concentration of one HCV patient, and the bars are the mean with SD. Each dots in control represent the normalized concentration of MBL in the serum sample of one individual.

\section{Alignment of the Sequences}

When the sequence analyzed the 6bp deletion at position -324, AGGAAG -319 observed which located between the two previously detected SNPs -550 and -221 [Figure 2]. The deletion was detected in 12 samples, one in the HCV-ve, while the others in the HCV+ve samples. For comparison, 14 other samples were selected in both chronic and haemophilia as an $\mathrm{HCV}+\mathrm{ve}$ sample with no detected deletion in their sequences. Moreover, $25 \mathrm{HCV}$-ve samples were selected as control with the same age range as infected HCV patient's age.

The chromatogram of the deleted 6bp nucleotides (AGGAAG) was showed repeated mixed picks at position -324 to -319 in the MBL2 promoter region. Figure 2 presented the alignment of those sequence which performed between those sequence with deletion and those with no deletion. The alignment is done by online http://multalin.toulouse.inra.fr software. The alignment showed the deletion of 6bp of AGGAAG nucleotides at positions -324 to -319 . Three SNPs preceded the deletions at positions $-328,-336$ and -349 which A changed to G with different frequency among the sequences. Moreover, another SNP detected at a position $427 \mathrm{~A}>\mathrm{C}$ in all the sequence which the deletion included. The single mutations in the promoter region (-550 and -221) were homozygous for most of the samples, and the latter one was more frequent among all the sequences.

Other variations were detected as well in both promoter and the exon region Table 2. The SNPs of the promoter region were at positions $-550 \mathrm{G}>\mathrm{C},-427 \mathrm{~A}>\mathrm{C},-349 \mathrm{~A}>\mathrm{G},-336 \mathrm{~A}>\mathrm{G}$, $328 \mathrm{~A}>\mathrm{G}$ and $-221 \mathrm{C}>\mathrm{G}$. The most frequent variation among those sequence had a $6 \mathrm{bp}$ deletions at positions -427 and -221 . The SNPs in the coding region were at codon 54 and 57 while no SNPs were detected in the codon 52. The variations in the exon region were detected to be less frequent among the selected samples.

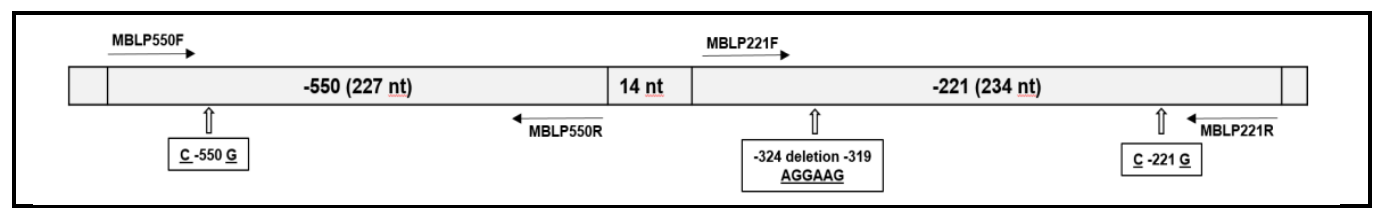




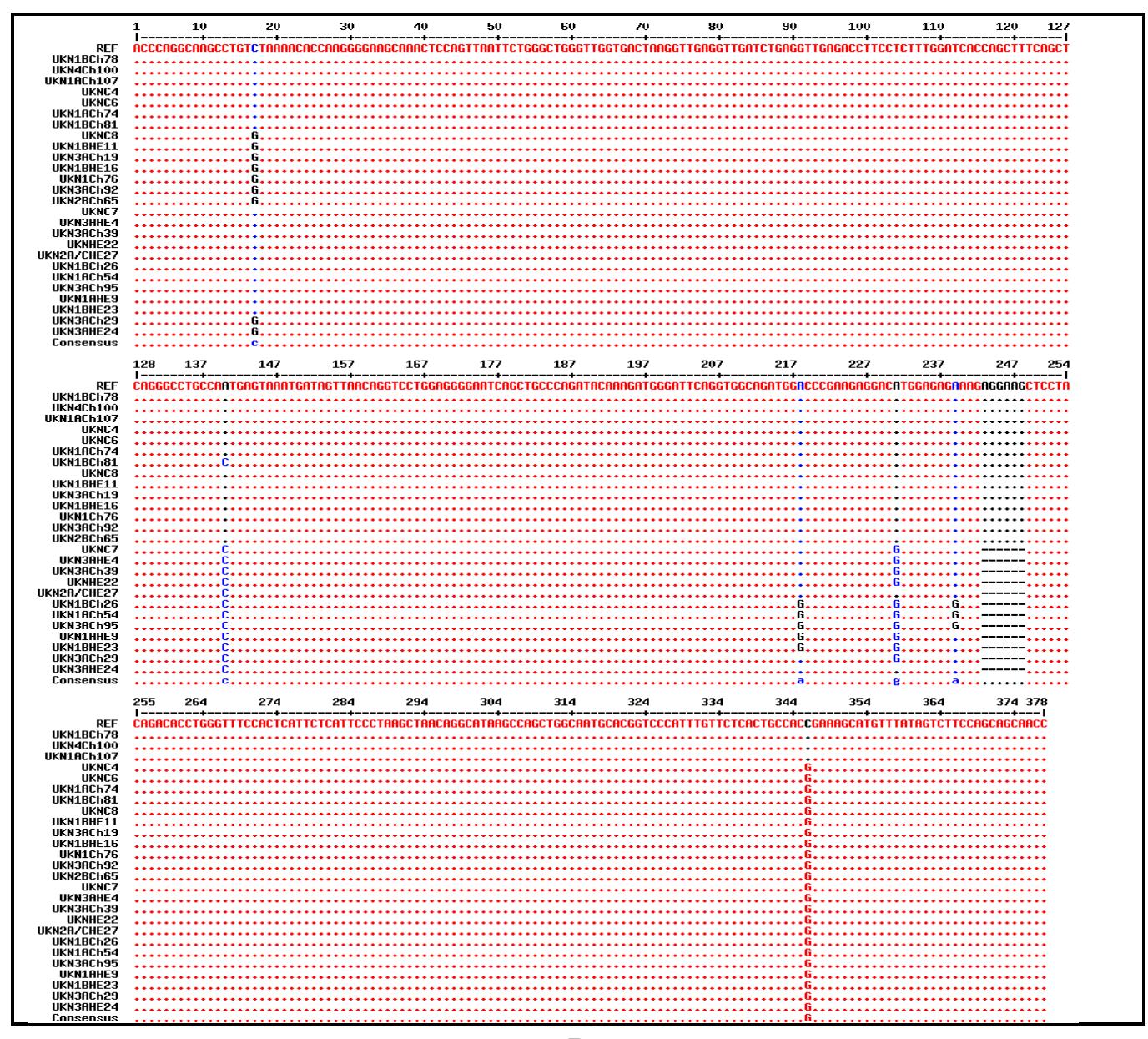

B

Figure 2: Sequence Alignment of the $M B L 2$ Promoter. A) Schematic Map Showing the 6bp Deletion Position. Two primers used to amplify $475 \mathrm{nt}$; then for confirmation of the deletion, two internal primers were used when cloned and re-sequenced. B) The alignment showing the 6bp deletion (-324 to -319$)$ preceded by three SNPs. The first SNP at position $-550 \mathrm{C}>\mathrm{G}$ followed by SNP at position $-427 \mathrm{~A}>\mathrm{T}$. The three SNPs at position $-328,-336$ and -349 were preceded the deletion. The last SNPs showed in the alignment is at position $-221 \mathrm{C}>\mathrm{G}$.

Table 2: Detected SNPs in the Selected Samples for the Analysis of the 6bp Deletion in the MBL2 promoter. The SNPs in both -550 and -221 of the promoter and the variations in the exon region (Codon 52,54 and 57) were showed as a genotype.

\begin{tabular}{|c|c|c|c|c|c|c|c|c|c|c|}
\hline Samples & -550 & -427 & -349 & -336 & -328 & $-324-319$ & -221 & $\begin{array}{c}\text { Codon } \\
52\end{array}$ & $\begin{array}{c}\text { Codon } \\
54\end{array}$ & $\begin{array}{c}\text { Codon } \\
57\end{array}$ \\
\hline & $\begin{array}{c}G>C \\
(H / L)\end{array}$ & $\mathbf{A}>\mathbf{C}$ & $A>\mathbf{G}$ & $\mathbf{A}>\mathbf{G}$ & $\mathbf{A}>\mathbf{G}$ & AGGAAG & $\begin{array}{r}\mathbf{C}>\mathbf{G} \\
(\mathbf{X} / \mathbf{Y})\end{array}$ & $\begin{array}{c}C>T \\
(A / D)\end{array}$ & $\begin{array}{l}\mathbf{G}>\mathbf{A} \\
(\mathbf{A} / \mathbf{B})\end{array}$ & $\begin{array}{c}\mathbf{G}>\mathbf{A} \\
(\mathbf{A} / \mathbf{C})\end{array}$ \\
\hline \multicolumn{11}{|c|}{ HCV-ve Control } \\
\hline UKNC4 & H & $\mathbf{A}$ & $\mathbf{A}$ & $\mathbf{A}$ & $\mathbf{A}$ & DEL & $\mathbf{Y}$ & & & \\
\hline UKNC6 & $\mathbf{L}$ & $\mathbf{A}$ & $\mathbf{A}$ & $\mathbf{A}$ & $\mathbf{A}$ & DEL & $\mathbf{Y}$ & & & \\
\hline UKNC7 & $\mathbf{H}$ & C & $\mathbf{A}$ & G & $\mathbf{A}$ & AGGAAG & $\mathbf{Y}$ & & & \\
\hline UKNC8 & $\mathbf{H}$ & $\mathbf{A}$ & $\mathbf{A}$ & $\mathbf{A}$ & $\mathbf{A}$ & DEL & $\mathbf{Y}$ & & & \\
\hline $\begin{array}{c}\text { HCV+ve wit } \\
\text { Deletion }\end{array}$ & & & & & & & & & & \\
\hline
\end{tabular}




\begin{tabular}{|c|c|c|c|c|c|c|c|c|c|c|}
\hline UKN1BCh26 & $\mathbf{L}$ & $\mathrm{C}$ & G & G & G & DEL & $\mathbf{Y}$ & & & \\
\hline UKN3ACh29 & H & $\mathrm{C}$ & A & G & A & DEL & $\mathbf{Y}$ & & & \\
\hline UKN3ACh39 & $\mathbf{L}$ & $\mathrm{C}$ & $\mathbf{A}$ & G & $\mathbf{A}$ & DEL & $\mathbf{Y}$ & & & \\
\hline UKN1ACh54 & $\mathbf{L}$ & $\mathrm{C}$ & G & G & G & DEL & $\mathbf{Y}$ & $\mathbf{A}$ & $\mathbf{A}$ & $\mathbf{A}$ \\
\hline UKN3ACh95 & $\mathbf{L}$ & $\mathrm{C}$ & G & G & G & DEL & $\mathbf{Y}$ & & & \\
\hline UKN1AHaem9 & $\mathbf{L}$ & $\mathrm{C}$ & G & G & $\mathbf{A}$ & DEL & Y & $\mathbf{A}$ & $\mathbf{A}$ & $\mathbf{A}$ \\
\hline UKN1BHaem23 & L & $\mathrm{C}$ & G & G & $\mathbf{A}$ & DEL & $\mathbf{Y}$ & A & B & $\mathbf{A}$ \\
\hline UKN3AHaem24 & $\mathbf{H}$ & C & A & $\mathbf{A}$ & $\mathbf{A}$ & DEL & $\mathbf{Y}$ & $\mathbf{A}$ & $\mathbf{A}$ & $\mathbf{A}$ \\
\hline UKN2AHaem27 & $\mathbf{L}$ & $\mathrm{C}$ & A & $\mathbf{A}$ & $\mathbf{A}$ & DEL & Y & $\mathbf{A}$ & $\mathbf{A}$ & $\mathrm{C}$ \\
\hline UKN3AHaem4 & $\mathbf{L}$ & $\mathrm{C}$ & $\mathbf{A}$ & G & $\mathbf{A}$ & DEL & $\mathbf{Y}$ & $\mathbf{A}$ & B & $\mathbf{A}$ \\
\hline UKNHaem22 & $\mathbf{L}$ & $\mathrm{C}$ & A & G & A & DEL & $\mathbf{Y}$ & $\mathbf{A}$ & $\mathbf{A}$ & C \\
\hline \multicolumn{11}{|l|}{$\begin{array}{c}\text { HCV+ve without } \\
\text { Deletion }\end{array}$} \\
\hline UKN3ACh19 & $\mathbf{H}$ & $\mathbf{A}$ & A & $\mathbf{A}$ & $\mathbf{A}$ & AGGAAG & Y & $\mathbf{A}$ & $\mathbf{A}$ & $\mathbf{A}$ \\
\hline UKN2BCh65 & $\mathbf{H}$ & $\mathbf{A}$ & $\mathbf{A}$ & $\mathbf{A}$ & $\mathbf{A}$ & AGGAAG & $\mathbf{Y}$ & & & \\
\hline UKN1ACh74 & $\mathbf{L}$ & A & A & $\mathbf{A}$ & $\mathbf{A}$ & AGGAAG & $\mathbf{Y}$ & $\mathbf{A}$ & $\mathbf{A}$ & $\mathbf{A}$ \\
\hline UKN1Ch76 & $\mathbf{H}$ & $\mathbf{A}$ & A & $\mathbf{A}$ & $\mathbf{A}$ & AGGAAG & $\mathbf{Y}$ & $\mathbf{A}$ & $\mathbf{A}$ & $\mathbf{A}$ \\
\hline UKN1BCh78 & $\mathbf{L}$ & $\mathbf{A}$ & $\mathbf{A}$ & $\mathbf{A}$ & $\mathbf{A}$ & AGGAAG & $\mathbf{X}$ & $\mathbf{A}$ & $\mathbf{A}$ & $\mathbf{A}$ \\
\hline UKN1BCh81 & $\mathbf{L}$ & C & $\mathbf{A}$ & $\mathbf{A}$ & $\mathbf{A}$ & AGGAAG & $\mathbf{Y}$ & $\mathbf{A}$ & $\mathbf{A}$ & $\mathbf{A}$ \\
\hline UKN3ACh92 & $\mathbf{H}$ & $\mathbf{A}$ & A & $\mathbf{A}$ & $\mathbf{A}$ & AGGAAG & $\mathbf{Y}$ & & & \\
\hline UKN4Ch100 & $\mathbf{L}$ & $\mathbf{A}$ & $\mathbf{A}$ & $\mathbf{A}$ & $\mathbf{A}$ & AGGAAG & $\mathbf{X}$ & & & \\
\hline UKN1ACh107 & $\mathbf{L}$ & $\mathbf{A}$ & A & $\mathbf{A}$ & $\mathbf{A}$ & AGGAAG & $\mathbf{X}$ & & & \\
\hline UKN1ACh123 & $\mathbf{H}$ & $\mathbf{A}$ & A & $\mathbf{A}$ & $\mathbf{A}$ & AGGAAG & $\mathbf{Y}$ & & & \\
\hline UKN1Haem7 & $\mathbf{L}$ & $\mathbf{A}$ & $\mathbf{A}$ & $\mathbf{A}$ & $\mathbf{A}$ & AGGAAG & $\mathbf{X}$ & $\mathbf{A}$ & $\mathbf{A}$ & $\mathrm{C}$ \\
\hline UKN1Haem10 & $\mathbf{L}$ & A & A & $\mathbf{A}$ & $\mathbf{A}$ & AGGAAG & $\mathbf{X}$ & $\mathbf{A}$ & $\mathbf{A}$ & $\mathbf{A}$ \\
\hline UKN1BHaem11 & $\mathbf{H}$ & $\mathbf{A}$ & $\mathbf{A}$ & $\mathbf{A}$ & $\mathbf{A}$ & AGGAAG & $\mathbf{Y}$ & $\mathbf{A}$ & $\mathbf{A}$ & $\mathbf{A}$ \\
\hline UKN1BHaem16 & $\mathbf{H}$ & A & A & A & $\mathbf{A}$ & AGGAAG & $\mathbf{Y}$ & A & $\mathbf{A}$ & $\mathbf{A}$ \\
\hline
\end{tabular}

\section{Relation between the Deletion and MBL Level}

Each patient had a different level of MBL during the entire period of treatment. The concentration in the samples with deletion ranges between 0.04 to $3.67 \mu \mathrm{g} \cdot \mathrm{mL}^{-1}$ and for samples not including the $6 \mathrm{bp}$ deletion range between 0.05 to $4.29 \mu \mathrm{g} \cdot \mathrm{mL}^{-1}$. The mean value of the MBL level were $1.89,2.48$ and $1.71 \mu \mathrm{g} \cdot \mathrm{mL}^{-1}$ for the healthy control, $\mathrm{HCV}+\mathrm{ve}$ without and $\mathrm{HCV}+\mathrm{ve}$ with deletion, respectively. According to the ANOVA analysis, a significant (P $<0.0001)$ variation observed between the mean of the MBL level during the entire period of infection and treatment in each patients sample [Figure 3]. 


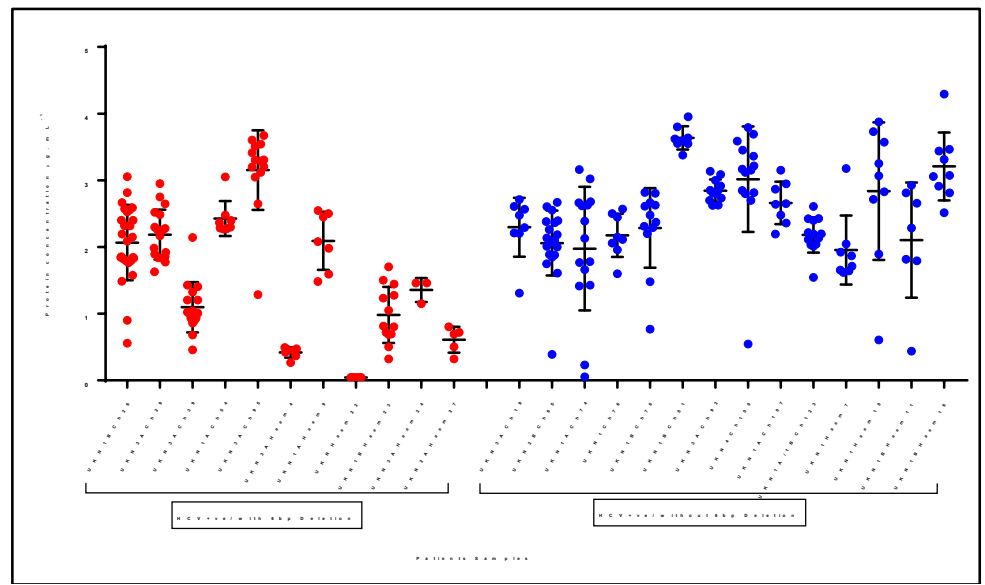

Figure 3: The Level of MBL for Each Patient at a Different Time of Infection and Treatment. Each circle represents one sample. The red circles represent samples with $6 \mathrm{bp}$ deletion while the blue circles represent samples without deletion. The black bars are the mean with SEM.

A comparison between Median MBL concentration between different categories of HCV-ve, samples with $6 \mathrm{bp}$ deletion and samples without deletion was carried out to determine the general outcome of the $6 \mathrm{bp}$ nucleotide deletion in the $M B L 2$ promoter. Both ANOVA and Kruskal-Wallis tests showed $\mathrm{P}<0.05$, which considered significant variation in the levels of MBL in these groups [Figure 4]. The level of the HCV+ve samples with deletion was lower than both $\mathrm{HCV}$-ve and $\mathrm{HCV}+\mathrm{ve}$ without deletion. The HCV+ve samples with no deletion had a higher concentration of MBL than the other groups.

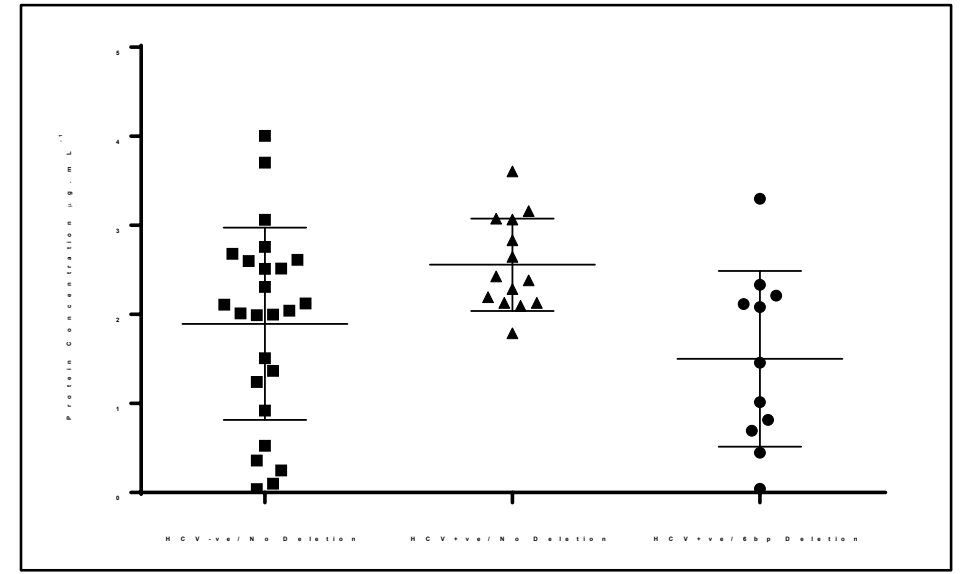

Figure 4: Comparison of the Median MBL Level in patients with and without 6bp deletion in the $M B L 2$ promoter. Each dot represents a median concentration of a patient in both HCV infected groups. The dots in the control group present the normalized level of MBL in a healthy individual. The black bar represents the mean and SD.

\section{Impact of the 6bp Deletion on the Treatment Outcome}

In order to get the answer for the effect of the deletion in the $M B L 2$ promoter on the response to therapy, we grouped the patients based on the treatment outcome into NR, RR and SVR [Figure 5]. MBL level increased among the groups of the samples which the deletion not detected within the range of 1.8 to above $3 \mu \mathrm{g} \cdot \mathrm{mL}^{-1}$. Our analysis showed a significant impact of the $6 \mathrm{bp}$ deletion on the NR group via decreasing the level of this protein below $1 \mu \mathrm{g} \cdot \mathrm{mL}^{-1}$ in most of the serum samples. However, the 6bp deletion in the promoter has not changed the level among the SVR patients. The concentration of MBL among the RR patients were not 
showed noticeable impact because of the low number of patients in this group in comparison to other groups.

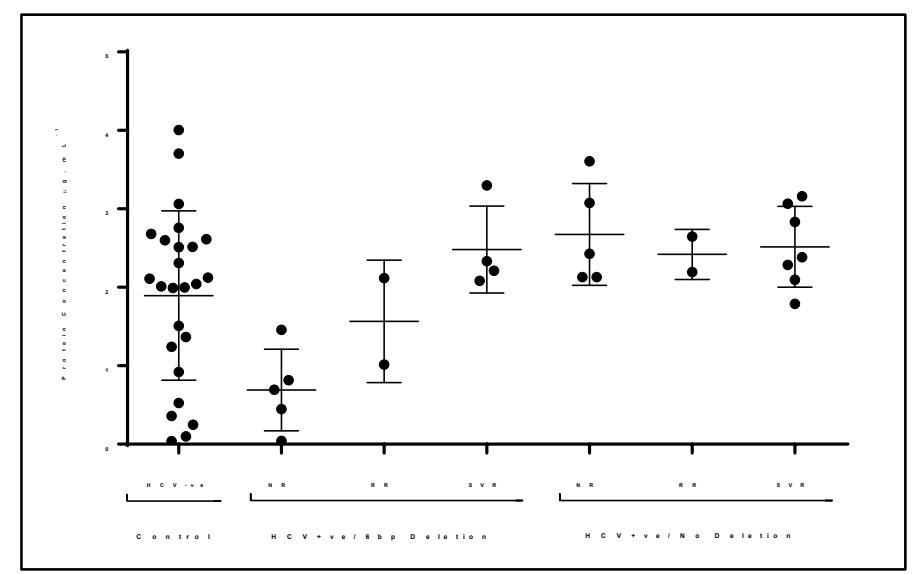

Figure 5: Effect of the $M B L 2$ 6bp Deletion on the Treatment Response. The HCV infected patients were grouped based on the response to treatment to non-responders (NR), relapsed responder (RR) and sustained virological responder (SVR). Each dots present the median concentration of the MBL protein in a patient. The black bars are the mean and SE.

\section{DISCUSSION}

In this study, six nucleotides [AGGAAG] deleted in the $M B L 2$ promoter that located between the two previously detected SNPs at -550 (rs11003125) and -221 (rs7096206) at position -319 to -324 . Notably, this deletion was more frequent among non-responders patients. Moreover, some other SNPs at position $-328,-336,-349$ and -427 were preceded the deletion. To our knowledge, no previous studies are pointing to these SNPs and mutation that we investigated. The MBL levels were elevated when the infection started (Figure 1), then this level changed during treatment. It is worth noted that these mutations and the deletion reduce the level of MBL to be lower than $1 \mu \mathrm{g} \cdot \mathrm{mL}^{-1}$, in comparison to that participant which were homozygous allele for -221. As well as, the low level of MBL was detected in comparison to the level of both L-ficolin and $\mathrm{H}$ - ficolin in most of the HCV-infected haemophiliac patients.

Many studies were interested in the innate immunity proteins, specifically, MBL, which may be due to its impact in the increasing the activity of the complement system, it is oligomerization difference, and level in the serum. The concentration of this protein should be considered because it is fluctuated during the entire lives depend on the age and environment $[16,24,25]$. Eventually, the level of MBL changed depend on the presence of different mutations observed in the $M B L 2$ gene precisely in both exon and promoter. Madsen and his colleagues have first reported the relationship between the level and different variant allele at position -221 [20]; also it has been shown that different haplotype in the promoter (HY, LY, and LX) show association with high, medium, and low levels of MBL in the serum [26]. In this study, the homozygous SNPs at -221 were more frequent in most of the HCV seropositive samples, and this agreed with the result published by Brown [27]. While due to the deletion of the six nucleotide in the promoter, the level reduced to be less than $1 \mu \mathrm{g} \cdot \mathrm{mL}^{-1}$. Regarding the SNPs at -550 promoter, only some of the patients were heterozygous, and it has been proven that the SNP at this position has a low impact on the MBL level [19, 28, 29].

Supporting the relation between SNPs and the MBL level recent studies pointing out that these SNPs produce a genetic balance which could explain the degree of difference in many populations $[10,28]$ also affect the number of lectin domains per molecule [2]. In general, the concentration below $0.1 \mu \mathrm{g} . \mathrm{mL}^{-1}$ was considered as MBL deficiency [8]. Our results showed that this deficiency led to non-responding or relapsed to the treatment [Figure 5] in most of the 
patients who associate to the viral persistence and opsonic deficiency [19, 28, 30]. This result agreed with the Study by Matsushita [31] on a Japanese population, which concluded that people infected with HCV and with the low level of MBL were less response to interferon. It has been reported that MBL deficiency due to the SNP at -221 position could be beneficial for the host [10] and could be used as a marker for development of the disease to Hepatocellular Carcinoma [32]. In a new study on a group of people infected with HBV revealed that the polymorphism in the $M B L 2$ gene act as a modifier for the susceptibility of the virus and progression of the disease [33].

On the other hand, some other researcher stated, no relation observed between the MBL level and the SNPs. Our results showed that some of the patients responded to the treatment despite the SNPs in the -221 promoter which may be due to the high level of other PRRs [Figure 6] [34] or the genotype of the virus [35, 36]. The last result agreed with Kilpatrick, which demonstrated that there is no connection between the concentration of MBL and vulnerability to HCV infection [37], disease severity or therapy response [38]. Interestingly, Kilpatrick showed a slight relationship between the high level of MBL and chronicity of HCV [37]. However, Zupin [39] were reported the association of the SNPs with SVR instead of susceptibility to HCV or viral clearance.

The level of all other PRRs should be encountered when studying the immune system. The level of both ficolins ( $\mathrm{H}$ and $\mathrm{L}$ ) have fluctuated with the level of MBL during the treatment and a balance observed with each protein in most of the patients [data not showed]. For instance, when the level of MBL is low, the level of L-ficolin, H-ficolin or both was high, and this may be due to the necessity of compensation within the lectin pathway. It has been reported that when MBL deficient the level of L-ficolin increased [40] due to the genetic balance and importance of the reparation in the immune system [41].

\section{CONCLUSION}

This study is confirming the effect of the SNPs in the $M B L 2$ promoter from the selected samples of European background. The high level of MBL in most of the serum samples could be due to low variations in the structural gene which thought to effects on the level of this protein which lead to the severe cases of these patients. Furthermore, the low level of this protein may be due to the presence of the mutation at position -221 in most of the sequences. The existence of the new deletion with other polymorphisms in the MBL2 gene promoter of significantly reduce the quantity of the MBL protein in $\mathrm{HCV}$-infected patients and precisely among non-responder. This deletion could be a biomarker for the progression of the disease due to not responding to the treatment. For more confirmation, more samples with the different ethnic group should be included, as well as; the control group should be from the same background with the infected patients. The expression of the protein level should be studied and compared to the serum protein level. More work needs to determine the actual impact of all the new SNPs on protein concentration and disease severity. Lastly, detecting the polymorphisms in the structural gene of $M B L 2$ and observing the associations with this deletion could answer many questions regarding the response to the treatment.

\section{REFERENCE}

[1] A. W. Tarr, R. A. Urbanowicz, and J. K. Ball, "The role of humoral innate immunity in hepatitis C virus infection," Viruses, vol. 4, pp. 1-27, Jan 2012.

[2] K. S. Brown, M. J. Keogh, A. M. Owsianka, R. Adair, A. H. Patel, J. N. Arnold, et al., "Specific interaction of hepatitis $\mathrm{C}$ virus glycoproteins with mannan-binding lectin inhibits virus entry," Protein Cell, vol. 1, pp. 664-74, Jul 2010.

[3] J. Liu, M. A. Ali, Y. Shi, Y. Zhao, F. Luo, J. Yu, et al., "Specifically binding of L-ficolin to N-glycans of HCV envelope glycoproteins E1 and E2 leads to complement activation," Cell Mol Immunol, vol. 6, pp. 235-44, Aug 2009.

[4] T. Amet, M. Ghabril, N. Chalasani, D. Byrd, N. Hu, A. Grantham, et al., "CD59 incorporation protects hepatitis C virus against complement-mediated destruction," Hepatology, vol. 55, pp. 354-63, Feb 2012.

[5] A. Ejaz, E. Steinmann, Z. Banki, Anggakusuma, S. Khalid, S. Lengauer, et al., "Specific acquisition of functional CD59 but not CD46 or CD55 by hepatitis C virus," PLoS One, vol. 7, p. e45770, 2012. 
[6] A. Saeed, K. Baloch, R. J. Brown, R. Wallis, L. Chen, L. Dexter, et al., "Mannan binding lectin-associated serine protease 1 is induced by hepatitis $\mathrm{C}$ virus infection and activates human hepatic stellate cells," Clin Exp Immunol, vol. 174, pp. 265-73, Nov 2013.

[7] K. S. Brown, M. J. Keogh, N. Tagiuri, M. J. Grainge, J. S. Presanis, S. D. Ryder, et al., "Severe fibrosis in hepatitis $\mathrm{C}$ virus-infected patients is associated with increased activity of the mannan-binding lectin (MBL)/MBL-associated serine protease 1 (MASP-1) complex," Clin Exp Immunol, vol. 147, pp. 90-8, Jan 2007.

[8] S. Thiel, "Complement activating soluble pattern recognition molecules with collagen-like regions, mannan-binding lectin, ficolins and associated proteins," Mol Immunol, vol. 44, pp. 3875-88, Sep 2007.

[9] M. R. Hamed, R. J. P. Brown, C. Zothner, R. A. Urbanowicz, C. P. Mason, A. Krarup, et al., "Recombinant Human L-Ficolin Directly Neutralizes Hepatitis C Virus Entry," J Innate Immun, 2014.

[10] R. M. Dommett, N. Klein, and M. W. Turner, "Mannose-binding lectin in innate immunity: past, present and future," Tissue Antigens, vol. 68, pp. 193-209, Sep 2006.

[11] T. Hummelshoj, L. Munthe-Fog, H. O. Madsena, R. B. Simb, and P. Garred, "Comparative study of the human ficolins reveals unique features of Ficolin-3 (Hakata antigen)," Molecular Immunology vol. 45, pp. 1623-1632, 2008.

[12] T. Fujita, M. Matsushita, and Y. Endo, "The lectin-complement pathway - its role in innate immunity and evolution," Immunological Reviews, vol. 198, pp. 185-202, 2004.

[13] V. Garlatti, L. Martin, M. Lacroix, E. Gout, G. J. Arlaud, N. M. Thielens, et al., "Structural insights into the recognition properties of human ficolins," J Innate Immun, vol. 2, pp. 17-23, 2010.

[14] D. L. Jack, N. J. Klein, and M. W. Turner, "Mannose-binding lectin: targeting the microbial world for complement attack and opsonophagocytosis," Immunol Rev, vol. 180, pp. 86-99, Apr 2001.

[15] A. G. Kutikhin and A. E. Yuzhalin, "Inherited variation in pattern recognition receptors and cancer: dangerous liaisons?," Cancer Manag Res, vol. 4, pp. 31-8, 2012.

[16] I. Terai, K. Kobayashi, M. Matsushitat, and T. Fujita, "Human serum mannose-binding lectin (MBL)associated serine protease- 1 (MASP-1): determination of levels in body fluids and identification of two forms in serum," Clin Exp Immunol, vol. 110, pp. 317-323, 1997.

[17] M. Sumiya, P. Tabona, T. Arai, J. A. Summerfield, M. Super, R. J. Levinsky, et al., "Molecular basis of opsonic defect in immunodeficient children," The Lancet, vol. 337, pp. 1569-1570, 1991/06/29 1991.

[18] J. A. Summerfield, S. D. Ryder, M. Sumiya, M. Thursz, A. Gorchein, M. A. Monteil, et al., "Mannose binding protein gene mutations associated with unusual and severe infections in adults," Lancet, vol. 345, pp. 886-89, 1995.

[19] C. L. Thio, T. Mosbruger, J. Astemborski, S. Greer, G. D. Kirk, S. J. O'Brien, et al., "Mannose binding lectin genotypes influence recovery from hepatitis B virus infection," J Virol, vol. 79, pp. 9192-6, Jul 2005.

[20] H. O. Madsen, P. Garred, S. Thiel, J. A. Kurtzhals, L. U. Lamm, L. P. Ryder, et al., "Interplay between promoter and structural gene variants control basal serum level of mannan-binding protein," $J$ Immunol, vol. 155, pp. 3013-20, Sep 151995.

[21] S. Pfaender, J. Brinkmann, D. Todt, N. Riebesehl, J. Steinmann, J. Steinmann, et al., "Mechanisms of methods for hepatitis C virus inactivation," Appl Environ Microbiol, vol. 81, pp. 1616-21, Mar 2015.

[22] K. S. Brown, S. D. Ryder, W. L. Irving, R. B. Sim, and T. P. Hickling, "Mannan binding lectin and viral hepatitis," Immunol Lett, vol. 108, pp. 34-44, Jan 152007.

[23] A. Krarup, S. Thiel, A. Hansen, T. Fujita, and J. C. Jensenius, "L-ficolin Is a Pattern Recognition Molecule Specific for Acetyl Groups," THE JOURNAL OF BIOLOGICAL CHEMISTRY, vol. 279 pp. 47513-47519, 2004.

[24] M. Scorza, R. Liguori, A. Elce, F. Salvatore, and G. Castaldo, "Biological role of mannose binding lectin: From newborns to centenarians," Clin Chim Acta, vol. 451, pp. 78-81, Dec 72015.

[25] I. Terai and K. Kobayashi, "Perinatal changes in serum mannose-binding protein (MBP) levels," Immunol Lett, vol. 38, pp. 185-7, Nov 1993.

[26] A. M. Oudshoorn, F. A. van den Dungen, K. P. Bach, I. Koomen, W. P. Fetter, A. Catsburg, et al. "Mannose-binding lectin in term newborns and their mothers: genotypic and phenotypic relationship," Hum Immunol, vol. 69, pp. 344-8, Jun 2008.

[27] E. E. Brown, M. Zhang, R. Zarin-Pass, T. Bernig, F.-C. Tseng, N. Xiao, et al., "MBL2 and Hepatitis C Virus Infection among Injection Drug Users," BMC Infectious Diseases vol. 8, 2008.

[28] P. Garred, F. Larsen, H. O. Madsena, and C. Koch, "Mannose-binding lectin deficiency-revisited," Molecular Immunology, vol. 40, pp. 73-84, 2003.

[29] R. Steffensen, S. Thiel, K. Varming, C. Jersild, and J. C. Jensenius, "Detection of structural gene mutations and promoter polymorphisms in the mannan-binding lectin (MBL) gene by polymerase chain reaction with sequence-specific primers," Journal of Immunological Methods, vol. 241, pp. 33-42, 2000.

[30] P. Garred, S. Thiel, H. O. Madsen, L. P. Ryder, J. C. Jensenius, and A. Svejgaard, "Gene frequency and partial protein characterization of an allelic variant of mannan binding protein associated with low serum concentrations," Clin. exp. Immunol., vol. 90 pp. 517-521, 1992.

[31] M. Matsushita, M. Hijikata, Y. Ohta, K. Iwata, M. Matsumoto, K. Nakao, et al., "Hepatitis C virus infection and mutations of mannose-binding lectin gene MBL," Arch Virol, vol. 143, pp. 645-651, 1998.

[32] Y. Lin, C. Su, J. Niu, Z. Guo, and L. Cai, "Impact of mannose-binding lectin 2 polymorphism on the risk of hepatocellular carcinoma: a case-control study in Chinese Han population," J Epidemiol, vol. 25, pp. 387-91, 2015. 
[33] X. Gu, Q. Ji, H. Wang, M. Jiang, J. Yang, M. Fang, et al., "Genetic variants of mannose-binding lectin 2 gene influence progression and prognosis of patients with hepatitis B virus infection in China," Clin Res Hepatol Gastroenterol, Feb 52016.

[34] J. Liu, M. A. M. Ali, Y. Shi, Y. Zhao, F. Luo, J. Yu, et al., "Specifically Binding of L-ficolin to N-glycans of HCV Envelope Glycoproteins E1 and E2 Leads to Complement Activation," Cellular \& Molecular Immunology, vol. 6, pp. 235-244, 2009.

[35] J. M. Pawlotsky, "Therapy of hepatitis C: from empiricism to eradication," Hepatology, vol. 43, pp. S20720, Feb 2006.

[36] K. Sasaki, A. Tsutsumi, and N. Wakamiya, "Mannose-Binding Lectin Polymorphisms in Patients with Hepatitis C Virus Infection," Scandinavian Journal of Gastroenterology, vol. 35, pp. 960-965, 2009.

[37] D. C. Kilpatrick, T. E. S. Delahooke, C. Koch, M. L. Turner, and P. C. Hayes, "Mannan-binding lectin and hepatitis C infection," Clin Exp Immunol vol. 132, pp. 92-95, 2003.

[38] A. C. Vallinoto, R. F. da Silva, R. B. Hermes, I. S. Amaral, E. C. Miranda, M. S. Barbosa, et al., "Mannose-binding lectin gene polymorphisms are not associated with susceptibility to hepatitis $\mathrm{C}$ virus infection in the Brazilian Amazon region," Hum Immunol, vol. 70, pp. 754-7, Sep 2009.

[39] L. Zupin, V. Polesello, G. Alberi, G. Moratelli, S. L. Croce, F. Masutti, et al., "MBL2 genetic variants in HCV infection susceptibility, spontaneous viral clearance and peghylated-interferon plus ribavirin treatment response," Scand J Immunol, May 22016.

[40] M. Ishii, I. Ohsawa, H. Inoshita, G. Kusaba, K. Onda, M. Wakabayashi, et al., "Serum concentration of complement components of the lectin pathway in maintenance hemodialysis patients, and relatively higher levels of L-Ficolin and MASP-2 in Mannose-binding lectin deficiency," Ther Apher Dial, vol. 15, pp. 4417, Oct 2011.

[41] H. Bjarnadottir, M. Arnardottir, and B. R. Ludviksson, "Frequency and distribution of FCN2 and FCN3 functional variants among MBL2 genotypes," Immunogenetics, vol. 68, pp. 315-25, May 2016. 